\title{
INTEGRASI ILMU DAN AGAMA DALAM MENYONGSONG PERADABAN BANGSA
}

\author{
Aminah \\ Institut Parahikma Indonesia (IPI) Gowa
}

\begin{abstract}
The presence of a civilization is a necessity. In such efforts, the integration between science and religion is a basic framework that can facilitate such efforts. In this context, science is seen as something of a physical nature while religion is seen as something that is metaphysical. The synthesis between the two became a theo-anthropocentric assimilation that gave birth to the magnum opus of civilization.
\end{abstract}

Keywords: Integration Science, Islam Religion, Civilization Nation

\section{PENDAHULUAN}

Dalam menjalani hidup ini manusia dibekali kemampuan untuk mengemban amanah di muka bumi ini. Manusia dipilih untuk membentuk peradaban di dunia, karena secara jasad maupun batin dan akal, manusia diciptakan dengan berbagai substansi untuk menyempurna. Fitrah manusia adalah menyempurna, hanya saja pandangan dunia tiap individu itu berbeda-beda sehingga berimplikasi pada bagaimana cara mereka menyikapi atau menghadapi tiap polemik yang ada. Tuhan menyebutkan beberapa ciri manusia dalam Al-Qur'an, diantaranya: a) Al Basyar yang bermakana bahwa manusia memiliki jasad dan organ biologis. Dalam hal ini manusia sama dengan binatang yang memiliki beberapa bagian organ tubuh yang vital dengan fungsi yang hampir mirip dengan manusia serta memiliki kebiasaan seperti makan, minum, dan istirahat, b) An Naas yang bermakna bahwa manusia adalah makhluk sosial yang saling bantu membantu, toleransi, saling menghormati satu sama lain, c) Al insan yang bermakna manusia adalah makhluq sempurna secara totalitas baik secara fisik, mental, intelektual, maupun spiritual.

Jika dilihat dari sudut pandang Al-insan, maka manusia adalah makhluq yang bisa menciptakan peradaban di permukaan bumi. Secara fitrawi, manusia cenderung pada kesempurnaan. Kesempurnaan tersebut bergantung pada epistemology yang dimiliki. Misalnya, epistemologi yang dimiliki adalah cara pandang materialis, maka mereka menilai segala hal yang sempurna hanya benilai aksiden. Hal yang bersifat aksiden tersebut adalah segala hal yang bisa di inderai seperi kecantikan, penampilan luar, dan kebersihan. Di sisi lain, jika seseorang mengunakan akalnya sebagai epistemologi lanjutan dai inderawi, maka ia bisa menilai segalanya secara objektif dan logis.

Peradaban hanya akan tercipta jika manusia mengaktualkan potensi al-insan dalam dirinya. Selain itu untuk mmbentuk peradaban maka agama dan ilmu adalah dua 
hal penting yang harus teraktual. Walaupun ada beberapa pahaman yang menganggap bahwa agama dan ilmu adalah dua hal yang tidak akan bertemu di satu titik, kajian ini akan membuktikan bahwa peradaban dengan cara mengintegrasikan agama dan ilmu bukanlah suatu hal yang nihil. Karena dengan menjadikan ilmu dan agama sebagai tonggaknya, maka kehidupan menjadi seimbang an bermakna.

\section{INTEGRASI ILMU DAN AGAMA}

Ilmu dalam bahasa lain juga disebut sains yang lebih rinci akan dibahas, sementara agama secara etimologi berasal dari bahasa Sangsekerta yang akar katanya adalah $a$ dan gama. A artinya tidak dan gama artinya kacau. Jadi, agama artinya tidak kacau atau teratur. Maksudnya, agama adalah peraturan yang dapat membebaskan manusia dari kekacauan yang dihadapi dalam hidupnya, bahkan menjelang matinya. ${ }^{1}$ Berikut adalah rincian pembahasan perkembangan ilmu dan agama dalam kerangka filosofis.

\section{A. Pandangan filosofis mengenai ilmu}

Umumnya ilmu dipandang dari segi materialis dan metafisika islam. Filsafat digunakan sebagai tolok ukur memahami hakikat realitas. Mengkaji filsafat tidak terlepas dari 3 hal, yakni pembahasan epistemologi (cara pandang manusia dalam memahami realitasa atau alat yang digunakan dalam memahami dan menilai realitas), ontologi (ilmu mengenai hakikat realitas berasarkan epistemologi yang digunakan), dan aksiologi (yang membahas tentang hasil dari memahami dan menilai realitas yang ada). Filsafat sebagai induk segala ilmu pengetahuan jugalah yang mengubah hal yang tadinya mitos menjadi logis.

Perkembangan ilmu pengetahuan secara garis besar atau dalam pandangan non Islam terbagi menjadi 3 yakni:

1. Era Renaisans (Abad Ke 15-16)

Renaisans merupakan era sejarah yang penuh dengan kejayaan gemilang perkembangan ilmu pengetahuan. Di era ini, tantangan gerakan reformasi terhadap kekuasaan tunggal dan supremasi Gereja Katolik Roma berkembang seiring dengan kejayaan humanisme. ${ }^{2}$ Sejarah mencatat bahwa penyempurnaan kesenian, keahlian dan ilmu yang diwujudkan dalam diri jenis serba bisa Leonardo da Vinci melejit di zaman ini. Selain itu penemuan percetakan (kira-kira 1440M) dan ditemukannya benua baru (1429M) oleh Columbus memberikan motivasi pada kalangan lain dalam kemajuan ilmu pengetahuan. Kelahiran kembali sastra di Inggris, Perancis dan Spanyol diwakili Shakespeare, Spencer, Rabelais, dan Ronsar. Seni musik juga mengalami perkembangan pesat.

1 Al-Asyraf, Pengertian Agama, https://abdain.wordpress.com/2010/01/03/pengertian-agama/, diakses pada tanggal 2 Februari 2017.

2 Ahmad Edi Purwanto, Perkembangan Filsafat Zaman Renaisans dan Modern, http://aepcitystudio.blogspot.co.id/2014/09/perkembangan-filsafat-zaman-renaisans.html, diakses pada tanggal 2 Februari 2017. 
Nicholas Copernicus (1473-1543) adalah seorang tokoh gereja ortodoks di era ini, ia menemukan bahwa matahari berada di pusat pada jagad raya, dan bumi memiliki dua macam gerak, yaitu berputar sehari-hari pada porosnya dan gerak tahunan mengelilingi matahari. Teorinya ini disebut Heliosentrisme, dimana matahari menjadi pusat jagad raya, bukan bumi sebagaimana yang dikemukakan oleh Ptolomeus yang diperkuat oleh pihak gereja. Teori Ptolomeus ini disebut Geosentrisme yang mempertahankan bumi sebagai pusat jagad raya.

Selain Copernicus, tokoh ternama disaat itu adalah Galileo (1546-1642) dengan penemuan lintas peluru, penemuan hukum pergerakan, dan penemuan tata bulan planet Jupiternya. Penemuan tata bulan Jupiter memperkokoh keyakinan Galileo bahwa tata surya bumi bersifat heliosentrik. Sebagai sarjana matematika dan fisika, Galileo menerima prinsip tata surya yang heliosentris. Galileo dapat pula membuat sebuah teropong bintang untuk melihat beberapa peristiwa angkasa secara langsung. Yang terpenting dan terakhir ditemukannya adalah planet Jupiter yang dikelilingi oleh empat buah bulan.

Galileo membagi sifat benda dalam dua golongan, yaitu pertama, golongan yang langsung mempunyai hubungan dengan metode pemeriksaan fisik, artinya yang mempunyai sifat-sifat primer (primary qualities) seperti berat, panjang dan lain-lain sifat yang dapat diukur. Kedua, golongan yang tidak mempunyai peranan dalam proses pemeriksaan ilmiah, disebut sifat-sifat sekunder (secondary qualities) seperti sifat warna, asam, manis, dan tergantung dari pancaindera manusia. Sejak itu, ilmu pada umumnya tidak dapat memeriksa sifat kehidupan, karena sifatnya subjektif, tidak dapat diukur, dan tidak dapat ditemukan satuan dasarnya. Hal itulah yang membuat Galileo dianggap sebagai pelopor perkembangan ilmu dan penemu dasar ilmu modern yang hanya berpegang pada soal-soal yang objektif saja.

Pada masa yang bersamaan, Tycho Brahe (1546-1601) menemukan bahwa adalah “benda-benda angkasa semuanya 'terapung bebas' dalam ruang angkasa”. Johannes Keppler (1571-1630) sebagai pembantu Tycho yang mengembangkan ilmu astronomi. Pada era itu juga ditemukan logaritma oleh Napier (1550-1617) berdasarkan basis e, yang kemudian diubah ke dalam dasar 10 oleh Briggs (lahir tahun 1615) dan kemudian diperluas oleh Brochiel de Decker (lahir tahun 1626). Desarque (1593-1662) ditemukan Projective Geometry, Sedangkan Fermat mengembangkan Ortogonal Coordinate System seperti Descartes. Di samping itu, ia juga melaksanakan penelitian teori al-Jabar berkenaan dengan bilangan-bilangan dan soal-soal dalam tangan Newton dan Leibniz kemudian akan menjelma sebagai perhitungan diferensial integral (calculus). Fermat bersama-sama Pascal menyusun dasar perhitungan statistik. Sumbangsih penemuanpenemuan di era ini selanjutnya dikembangkan di era modern.

\section{Era Modern}

Tokoh yang berperan besar di awal era ini adalah Isaac Newton (1643-1727) dan Leibniz (1646-1716). Lahirnya teori gravitasi, perhitungan calculus, dan optika 
merupakan karya besar Newton. . Joseph Black (1728-1799) dikenal sebagai pelopor dalam pemeriksaan kualitatif, ia menemukan gas $\mathrm{CO}^{2}$. Ia melakukan pemanasan terhadap kapur. Demikian pula Henry Cavendish (1731-1810) memeriksa gas yang terjadi jika serbuk besi disiram dengan asam dan menghasilkan hawa yang dapat dinyalakan.

Sarjana lain, seperti Joshep Prestley (1733-1804) menemukan sembilan macam hawa No dan Oksigen yang antara lain dapat dihasilkan oleh tanaman. Oksigen ini dapat menyegarkan hawa yang tidak dapat lagi menunjang pembakaran. Antonine Laurent Lavoiser (1743-1794) adalah sarjana yang meletakkan dasar ilmu kimia. Perkembangan ilmu pada abad ke-18 telah melahirkan ilmu seperti taksonomi, ekonomi, kalkulus dan statistika. Di abad ke-19 muncul pharmokologi, geofisika, geomorfologi, palaentologi, arkeologi, logika matematika, mekanika quantum, fisika nuklir, kimia nuklir, radiobiologi, oceonografi, antropologi budaya, psikologi dan lain-lain.

Masa kini dimulai pada abad ke-19 dan 20 dengan timbulnya berbagai aliran yang berpengaruh seperti positvisme, marxisme, eksistensialisme, pragmatisme, neo kantianisme, neo tomisme, dan fenomenologi. Aliran-aliran ini sangat terikat oleh keadaan negara maupun lingkungan bahasa sehingga dalam perkembangan terakhir lahirlah filsafat analitis yang lahir sejak tahun 1950. Positivisme oleh filusuf Auguste Comte (1798-1857) seorang sosiolog pertama menyatakan bahwa pemikiran setiap manusia, setiap ilmu dan pola pikir tiap suku pada umumnya melewati tiga tahap yaitu: 1) Tahap teologis dimana manusia masih mempercayai hal bersifat mistis, 2) Tahap metafisis sebagai masa transisi antara tahap teologis ke fase ilmiah, 3) Tahap positif ilmiah adalah fase dimana segala hal dikatakan benar ketika dinilai secara ilmiah berdasarkan eksperimen, pengalaman, atau penelitian observatif.

\section{Era Posmodernisme}

Sejarah mencatat awal munculnya posmodernisme adalah pada tanggal 15 Juli 1972 di St. Louis Amerika Serikat. ${ }^{3}$ Namun hal ini sampai sekarang sebenarnya masih dalam perdebatan ramai karena setiap disiplin ilmu akan melihatnya engan cara yang berbeda. Ada 15 pola ide reaksi yang merupakan pecahan dari ide-ide asli dari belahan Barat dan berfungsi sebagai subjek perbincangan di Indonesia anatara lain: 1) ide difference berfungsi melihat kenyataan untuk mencapai nilai kemanusiaan melalui pengetahuan, 2) ide deconstruction yang digunakan untuk mengkritik tradisi filsafat oksidental, 3) ide politik sebagai sebuah bentuk manipulasi untuk menguasai atau mempertahankan kekuasaan politik, 4) ide epistemologi sebagai sebuah paradigm baru yang menjelaskan kembali kenyataan manusia, 5) ide logosentrisme yang diambil dari Derrida sebagai penolakan dominasi logos atau rasionalitas yang berubah menjadi mitos baru yakni sains dan teknologi, 6) ide tentang Tuhan dan Agama membuka

3 Radhar Panca Dahana, Jejak Posmodernisme: Pergulatan Kaum Intelektual Indonesia, (Yogyakarta, Bentang, 2004), h. 23 
kemungkinan munculnya sebuah kritik alternatif dalam pemikiran Islam terutama dengan pendekatan gaya Arkoun, 7) Seni diterapkan pada semua produksi artistik atau bentuk seni modern, 8) Arsitekturyang membawa slogan baru dalam dunia arsitektural dimana tak ada lagi totalitas dan prutanisme yang menyingkirkan opsi-opsi tradisional atau individual dalam karya arsitektural, 9) Ekonomi sebagai gagassan yang melakukan oposisi ekonomi modern, ekonomi dalam dominasi kuat kapitalisme, 10) Modernisme dimana posmodernisme telah membawa visi baru tentang hal ini temasuk semangat untuk menentang atau menolaknya. Sementara 5 hal lainnya adalah feminsme, ilmu ilmiah, bahasa, teknologi, dan Derrida. ${ }^{4}$

Dari rincian perkembangan ilmu secara ilmiah, dapat disimpulkan bahwa mayoritas memiliki epistemologi yang sama akni materialisme. Materialisme serta empiisme memiliki epistem atau alat yang sama dalam membaca realitas yakni hanya menggunakan indera. Aapun akal hanya menilai secara subjekif beasarkan apa yang diterima oleh indera sehingga hasil yang diperoleh besifat relative bahkan nisbi. Efek negatif yang muncul dalam keseharian adalah ketika menjalani sesuatu, selalu diukur dengan pandangan dunia materialistik. Contoh riil nya antara lain hidup hanya untuk memuaskan nafsu birahi, menumpuk harta, menzalimi bawahan (karyawan) karena melihat mereka seperti sekumpulan mesin yang siap bekerja setiap saat, korupsi, dan lain sebagainya.

Sementara itu Islam memandang ilmu sebagai cahaya. Rasulullah Muhammad S.A.W. bersabda bahwa "Ilmu adalah cahaya". Sebagaimana epistemologi Islam yang terdiri dari indera (yang berfungsi untuk mengenali realitas dari alam materi, khayal (yang berfungsi sebagai penyekutuan dan pembanding dalam khayalan dari semua objek-objek yang ditangkap oleh indera dan adapun alam yang dikenali oleh khayal adalah alam malakut atau alam barzakhi seperti di saat kita bermimpi, isaat itulah kita menangkap alammalakut), serta akal (yang berfungsi untuk menilai realitas, apakah benar atau salah. Adapun alam yang dikenal oleh akal disebut dengan alam akal seperti ketika manusia ingin mngetahui segala hal yang bersifat universal, maka di saat itulah dia menangkap Ialam akal).

Persepsi indera, khayal, dan akal inilah yang terapat dalam diri manusia (sebagai mikro kosmos). Sementara realitas adalah makro kosmos yang terdiri dari alam materi, alam khayal, dan alam akal. Cahaya yang dimaksud oleh nabi Muhammad S.A.W adalah Tuhan, beserta segala ciptaanNya. Hal ini selaras dengan Q.S./ Al-Nur [24]:35 yang berbunyi:

\footnotetext{
${ }^{4}$ Radhar Panca Dahana, Jejak Posmodernisme: Pergulatan Kaum Intelektual Indonesia, h. 50-55
} 


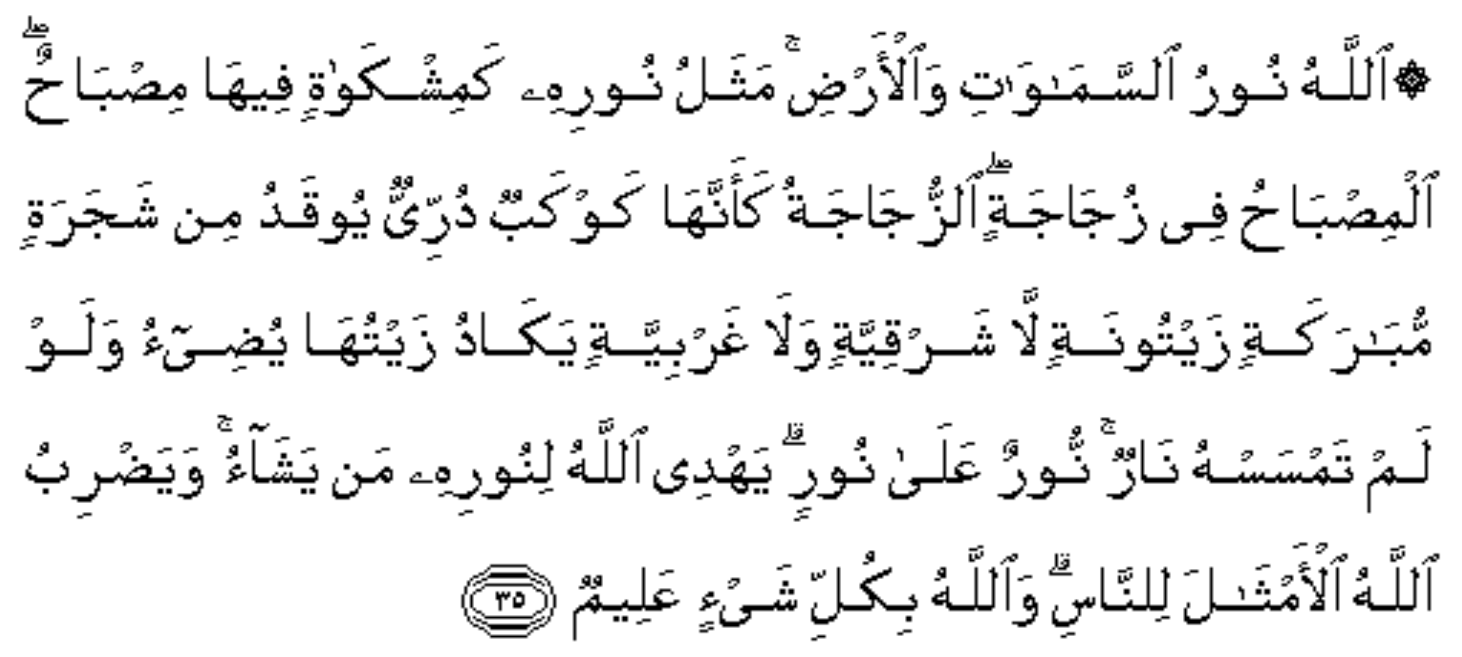

Artinya:

Allah (Pemberi) cahaya (kepada) langit dan bumi. Perumpamaan cahaya Allah, adalah seperti sebuah lubang yang tak tembus yang di dalamnya ada pelita besar. Pelita itu di dalam kaca (dan) kaca itu seakan-akan bintang (yang bercahaya) seperti mutiara, yang dinyalakan dengan minyak dari pohon yang berkahnya, (yaitu) pohon zaitun yang tumbuh tidak di sebelah timur (sesuatu) dan tidak pula di sebelah barat(nya) yang minyaknya (saja) hampir-hampir menerangi, walaupun tidak disentuh api. Cahaya di atas cahaya (berlapis-lapis), Allah membimbing kepada cahaya-Nya siapa yang dia kehendaki, dan Allah memperbuat perumpamaan-perumpamaan bagi manusia, dan Allah Maha Mengetahui segala sesuatu.

Ketiga alam yang dikenal oleh filusuf Islam tersebut adalah gradasi cahaya dari Sang Pemlik Cahaya yaitu Allah S.W.T. sebagai Sumbe Cahaya. Maka dari itu alam materi adalah alam yang paling jauh dari cahayaNya. Olehnya itu siapapun yang menjadikan dunia sebagai tujuan, jiwanya buta karena jauh dari cahaya Ilahi. Dia membunuh, serakah, mabuk harta karena mempertuhankan dunia dan isinya. Sebaliknya, siapapun yang beikhtiar menuju Tuhan, maka dia melampaui alam khayal dan alam akal dengan mensucikan jiwa dan jasad melalui ibadah, bedzikir, berbuat baik pada sesama, dan mensucikan akal dengan berpikir secara logis.

Selain itu, Islam tidak hanya mengenal ilmu yang bersifat ilmiah. Sebagaimana pembagian alam di atas, secara materi ilmu yang bisa didapatkan adalah ilmu fisika, kimia, ekonomi, dll. Dari alam khayal, manusia bisa mempelajari ilmu bahasa dan matematika, dan dari alam akal manusia mmpelajari tentang ilmu metafisika atau filsafat. Banyak para ilmuwan islam yang memiliki sumbangsih besar dalam pekembangan ilmu pengetahuan seperti Jabir bin Hayyan (Geber), Bapak Kimia Modern, Ibnu Rusyd (Averrous), Filsuf Muslim, Ibnu Sina (Avicenna): Bapak 
Kedokteran, Al-Biruni, Matematikawan Muslim, Al-Khawarizmi, Guru Aljabar Eropa, Ibnu Ismail Al-Jazari, Penemu Konsep Robotika Modern, dan sebagainya. ${ }^{5}$

\section{B. Pandangan filosofis mengenai agama}

Beberapa pemaparan mengenai pandangan filsafat kaum non muslim serta filsafat Islam di atas, maka dapat diketahui bahwa pastinya kaum materialistik ada yang tidak beragama. Mengapa? Karena Tuhan tidak dapat di inderai, dan manusia itu mati murni karna kehabisan energi dan mereka menganggap bahwa kehidupan dunia adalah kehidupan awal dan akhir. Maka dari itu kebanyakan kaum atheisme (tidak bertuhan) dikarenakan memiliki pandangan dunia materialisme.

Kita juga bisa menilik dari sejarah pemikiran seorang filosof yang merumuskan kembali pemikiran Plato (dalam Islam, pahaman Platonian ini berasarkan alam malakut), terutama dalam menjawab persoalan agama. Aliran ini dikenal dengan NeoPlatonisme yang dirintis oleh Plotinus (205-70 SM). Doktrin pokok Plotinus adalah tiga realitas, yaitu jiwa (soul), akal (nous), dan Yang baik (The Good). Hubungan ketiga unsur tersebut dikenal dengan Plotinus Trinity. Menurut Plotinus, Tuhan bukan untuk dipahami, tetapi untuk dirasakan. Akibatnya, orang-orang yang menghidupkan filsafat dimusuhi dan dibunuh. Di antara korban kefanatikan agama Kristen adalah Hypatia $(370-415){ }^{6}$

Sementara itu kaum theisme yang mengaku (beagama dan bertuhan) terbagi menjadi animisme (mempertuhankan benda-benda seperti pohon, dsb.), politheisme (percaya ada banyak Tuhan, dan monotheisme (percaya bahwa Tuhan itu Tunggal. Pada hakikatnya Tuhan itu Esa, hanya saja beberapa agama memiliki pahaman yang hanya sampai pada alam khayal atau malakut, sehingga melihat realitas alam kerangka majemuk seperti percaya pada banyaknya dewa. Jika dikaji secara filosofis, segala ciptaan yang ada di muka bumi ini pasti ada penciptanya.

Dalam memahami konsep penciptaan, kajian teologis beberapa agama mencoba menjawab berdasarkan kepercayaan dan epistemologi masing-masing. Islam memahami bahwa secara filosofis harus "Kausa Akhir yang tak tercipta”sebagai Penyebab Tunggal adanya alam semesta beserta isinya, Dialah yang disebut sebagai Tuhan yang terjewantahkan dalam beberapa agama dengan nama yang berbeda-beda seperti Allah S.W.T bagi orang muslim, Sang Hyang Widhi bagi orang Hinduisme Bali, bahkan kaum Kristiani mengakui Allah sebagai Tuhan mereka dalam Markus Pasal 12 ayat 9 yang berbunyi:

"Maka jawab Yesus kepadanya: "Hukum yang terutama inilah: dengarlah olehmu

${ }^{5}$ Abdul Rasyid, Ilmuwan Muslim di Abad kegelapan Eropa (kebangkitan \& Kejayaan islam pada zaman Kegelapan Eropa), https://www.facebook.com/notes/abdul-rasyid/ilmuwan-muslim-di-abadkegelapan-eropa-kebangkitan-kejayaan-islam-pada-zaman-keg/555981824478818/, diakses pada tanggal 3 Februari 2017.

6 Nanang Wijaya, Agama dan Filsafat Klasik, https://jalanpencerahan.wordpress.com/ artikel/agama-dalam-filsafat-klasik/, diakses pada tanggal 3 Februari 2017. 
hai Israil, adapun Allah Tuhan Kita, ialah Tuhan Yang Esa".

Dengan emikian kaum kristiani ada yang tidak mengakui Yesus sebagai Tuhan, jika mereka benar-benar memahami isi dari Kitab Injil ini. Hal ini sinergis dengan butir Pancasila sila ke 1 yang berbunyi "Ketuhanan Yang Maha Esa". Orang yan beragama juga percaya atau beriman bahwa akan ada alam setelah alam dunia yaitu akhirat/surge/neraka dan semua agama mengakui itu. Tiap agama juga memiliki suri tauladan seperti nabi Muhammad S.A.W bagi ummat islam, yesus bagi ummat kristen, serta para dewa bagi ummat hindu dan Buddha. Tiap agama juga mengajarkan hidup saling tolong menolong, saling menghormati dalam merintis perdamaian dan meraih kebahagiaan sejati.

Di Indonesia TAP MPR No. XVII/ 1998menyebutkan ada 8 kelompok hak asasi manusia yang iakui pemerintah sebagai hak yan tidak boleh diabaikan dan dirampas oleh siapapun, temasuk olh Negara sekalipun, yaitu hak untuk hidup, hak berkeluarga, hak mengembangkan diri, hak keadilan, hak kemerdekaan, hak berkomunikasi, hak keamanan, dan hak kesejahteraan. Adapun kebebasan beragama tertuang dalam pasal 13: Setiap orang bebas memeluk agamanya masing-masing dan untuk beribadat menurut agamanya dan kepercayaannya itu. ${ }^{7}$

Tujuan penciptaan manusia adalah untuk beribadah sebagaimana dalam Q.S. Addzariyat: 56-58 baik itu ibadah hati, lisan, dan anggota badan. ${ }^{8}$ Kitab suci Al-Qur'an juga menegaskan agar kita tidak memaksakan orang lain (yang beda keyakinan) untuk beribadah sesuai agama yang kita anut, sebagaimana Q.S./ Al-baqarah (2): 256 yang berbunyi:
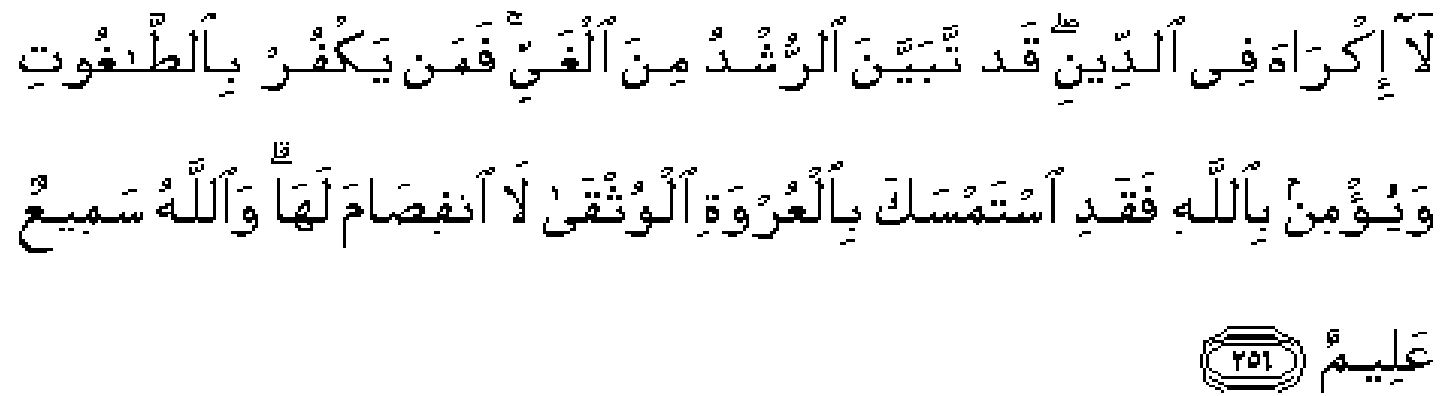

Artinya:

Tidak ada paksaan untuk (memasuki) agama (Islam); sesungguhnya telah jelas jalan yang benar daripada jalan yang sesat. Karena itu barangsiapa yang ingkar kepada Thaghut dan beriman kepada Allah, maka sesungguhnya ia telah berpegang kepada buhul tali yang amat kuat yang tidak akan putus. Dan Allah Maha Mendengar lagi Maha Mengetahui.

\footnotetext{
${ }^{7}$ Musdah Mulia, Islam dan Hak Asasi Manusia: Konsep dan Implementasi, (Yogyakarta, Naufan Pustaka, 2010), h. 34-35

${ }^{8}$ Syaikh DR. Shalih bin Fauzan Al-Fauzan, Kitab Tauhid 1, (Jakarta, Darul Haq, 1998), h. 76
} 


\section{Integrasi ilmu dan agama dalam membentuk peradaban}

Orang beragama pasti percaya atau beriman pada adanya Tuhan dan hal yang bersifat metafisika. Ironisnya, kekacauan justru tercipta oleh mereka yang mengaku beragama. Mengapa demikian? Hal ini disebabkan karena kuangnya kesadaran beragama secara totalitas. Sementara itu ada beberapa pahaman yang menganggap bahwa ilmu pengetahuan dan iman tak akan pernah bisa bersatu, dalam hal ini disebut dengan sekulerisme. Pemahaman sekuler ini berimplikasi pada cara manusia bersikap. Contoh nyata dalam kehidupan sehai-hari ketika seseorang bekerja, ianggap sebagai mengejar dunia, dan keika beribadah seperti sholat dianggap sebagai orang yang hanya mengejar akhirat. Padahal, urusan dunia dan akhirat adalah dua hal yang tak terpisahkan. Mencari rezki dengan cara yang halal agar bisa bersedekah dan membantu orang lain adalah salah satu cirri bahwasanya urusan dunia juga terkait dengan urusan akhirat ketika sinergis dengan aturan agama.

Peperangan yang terjadi di beberapa Negara bukan hanya menyangkut negara yang mengalami perang itu sendiri. Seperti perang di Palestina yan tak berkesudahan menarik simpati rakyat dunia dan memprotes negara penjajah seperti Israel beserta sekutunya. Disini terlihat adanya kesadaran manusia akan persoalan dunia yang bersifat menyeluruh. Dari segi ekonomi negara maju menaruh simpati pada negara miskin dengan hutangnya. Jadi memang semestinya, negara kaya membantu negara miskin. Tapi mengapa masih ada saja masyarakat yang tidak sejahtera?

Tindakan kekerasan masih terjadi dimana-mana. Konflik perang, kriminal, degradasi moral, perusakan lingkungan, kecanduan narkoba, KDRT, pelanggaran HAM, serta sikap tidak peduli pada Tuhan sebagai Sang Khaliq merupakan kelakuan yang merusak keselarasan alam semesta. Kesemuanya menunjukkan akan pentingnya perubahan cara pendekatan dan perubahan cara berpikir dalam mengatasi segala polemik kemanusiaan.

Fritjof Capra dalam bukunya The Tao of Physics dan The Turning Point berpendapat bahwa seluuh aspek iup ini dpengaruhi oleh perubahan paradigm ilmu pengetahuan seperti pengaruh pemikiran Timur, Taoisme. ${ }^{9}$ Adanya keselarasan antara fisika klasik Newton dan fisika kuantum. Fisika newton yang bersifat rasionalistis, serba terukur, mekanistik, logis, sebab-akibat, sangat berguna dalam perkembangan teknologi, ekonomi, fisika, biologi, kedokteran, dan psikologi. Namun dalam dunia mikro, fisika kuantum yang berlaku. Ternyata suatu sinar dapat bersifat sebagai partikel dan gelombang yang berbeda sifatnya. Dengan fisika kuantum di era modern ini, maka orang mulai merubah cara berpikir yang relative dan probabilistik. Fisika kuantum juga memutlakkan gagasan bahwa di dunia ini tidak ada sesuatu yang mutlak, yang paling benar, dan paling baik. Tiada yang Mutlak, Maha Benar, Maha Baik, kecuali Allah S.W.T.

\footnotetext{
${ }^{9}$ Agus Purwadianto, et.al, Jalan Paradoks, (Bandung, Teraju, 2004), h.8
} 
Bahkan ada fisikawan bernama Demitri Bolykov, yang sangat menggandrungi kajian serta riset-riset ilmiah, mengatakan bahwa pintu masuk ke Islamannya adalah fisika yang pada saat itu meneliti tentang perputaran bumi dan porosnya. ${ }^{10}$ Teori itu dinamakan "Gerak Integral Elektro Magno-Dinamika", dimana ayat-ayat Al Qur'an dan hadits nabi Muhammad S.A.W. juga menjelaskan tentang hal ini. ${ }^{11}$ Masih banyak lagi para ilmuwan yang masuk Islam dari hasil riset mereka yang juga terdapat dalam ajaran agama Islam.

Olehnya itu, tiap individu diharapkan memiliki kesadaran holistik atau menyeluruh agar kehidupan di alam semesta ini bisa selaras. Pendekatan Tao memang holistik alam menyatukan konsep (Yin dan Yang). Dengan demikian perlu dikembangkan pola pendidikan holistik dimana semua segi kemampuan manusia diperhatikan secara integral seperti kemampuan intelektual, emosional, sosial, fisik, artistik, kreativitas dan spiritual. Tiap pribadi akan menemukan dan mengembangkan identitasnya serta menemukan arti tujuan hidupnya melalui saling ketertarikan antara lingkungan, masyarakat, sesama, alam, serta Sang Pencipta.

Dengan adanya integrasi holistik tersebut maka peradaban di muka bumi ini bisa tercipta. Ilmu yang besifat sainstik dan agama yang membuat orang beriman patuh pada Penciptanya adalah kunci harmoni alam semesta. Harmonisasi alam semesta inilah yang membingkai peradaban manusia. Albert Einstein mengatakan: "Religion without science is blind. Science without religion is paralyzed" (Agama tanpa ilmu adalah buta, Ilmu tanpa agama adalah lumpuh)". ${ }^{12}$ Terciptanya peradaban adalah misi kerasulan Nabiyullah Muhammad S.A.W, sebagaimana termaktub dalam hadits shahih: " إنما بعثت لأتمم لأخلاقكارم " (Innama bu'itstu liutammima makarimal akhlaq) "Aku diutus untuk menyempurnakan akhlaq". Bahkan Allah S.W.T juga menegaskan bahwasanya nabi Muhammad S.A.W. adalah prototipe manusia yang berakhlaq sempurna dalam Q.S. 68 (al- Qalam): 4 dan QS. 33 (Al-Ahzab): 21. Masyarakat yang memiliki iman tanpa ilmu menjadi masyarakat yang terbelakang sedangkan masyarakat yang memiliki ilmu tanpa iman akan mnjadi bobrok moalnya. Karna itu seyogianya kita sebagai ummatnya mendukung misi peradaban atau akhlaq itu agar bisa berkibar dan terjewantahkan secara holistik selaras dengan ilmu pengetahuan di muka bumi ini.

Dalam konteks keindonesiaan, sila ke 2 dari butir Pancasila yan berbunyi: "Kemanusiaan yang adil dan beradab" menunjukkan bahwa misi kerosulan sejalan

10 Endah Hapsari, Ahli Fisika Ini Jadi Mualaf karena Matahari, Mengapa? (1) http://www.republika.co.id/berita/dunia-islam/mualaf/12/08/19/m812t8-ahli-fisika-ini-jadi-mualaf-karenamatahari-mengapa-1, diakses pada tanggal 3 Februari 2017.

${ }^{11}$ Rahmanhadiq, Al Qur'an dan Sains tentang Rotasi Bumi, http://www.qiroatipusat.or.id/2015/ 06/al-quran-dan-sains-tentang-rotasi-bumi.html, diakses pada tanggal 3 Februari 2017.

12 Ika Umaya Santi, Albert Einstein (Agama tanpa ilmu adalah buta, Ilmu tanpa agama adalah lumpuh), https://umayaika.wordpress.com/2012/04/24/albert-einstein-agama-tanpa-ilmu-adalahbuta-ilmu-tanpa-agama-adalah-lumpuh/, diakses pada tanggal 3 Februari 2017. 
dengan misi kebangsaan. Semoga peradaban mulia bisa tercipta di dunia ini terutama di tanah air Indonesia yang sama kita cintai ini.

\section{KESIMPULAN}

Integrasi antara ilmu dan agama dalam membingkai peradaban bukanlah hal yang mustahil. Teori peniikan holistik yang ditawarkan oleh Fritjof Capra dalam penyatuan antara teori fisika newtonian dan fisika kuantum telah membuktikan bahwa ilmu fisika dan metafisika sebagai bukti akan keselarasan antara ilmu dan agama (kaum yang beriman). Apapun latar belakang suku, agama, background pendidikan, integasi antara kecerdasan intelektual, emosional, serta spritual adalah kunci terciptanya peradaban. SALAM PERADABAN.

\section{DAFTAR PUSTAKA}

Abdul Rasyid, Ilmuwan Muslim di Abad kegelapan Eropa (kebangkitan \& Kejayaan islam pada zaman Kegelapan Eropa), https://www.facebook.com/notes/abdulrasyid/ilmuwan-muslim-di-abad-kegelapan-eropa-kebangkitan-kejayaan-islampada-zaman keg/555981824478818/, diakses pada tanggal 3 Februari 2017.

Agus Purwadianto, et.al, Jalan Paradoks, (Bandung, Teraju, 2004)

Ahmad Edi Purwanto, Perkembangan Filsafat Zaman Renaisans dan Modern, http://aepcitystudio.blogspot.co.id/2014/09/perkembangan-filsafat-zamanrenaisans.html, diakses pada tanggal 2 Februari 2017.

Al-Asyraf, Pengertian Agama, https://abdain.wordpress.com/2010/01/03/pengertianagama/, diakses pada tanggal 2 Februari 2017.

Endah Hapsari, Ahli Fisika Ini Jadi Mualaf karena Matahari, Mengapa? (1) http://www.republika.co.id/berita/dunia-islam/mualaf/12/08/19/m812t8-ahlifisika-ini-jadi-mualaf-karena-matahari-mengapa-1, diakses pada tanggal 3 Februari 2017.

Ika Umaya Santi, Albert Einstein (Agama tanpa ilmu adalah buta, Ilmu tanpa agama adalah lumpuh), $\quad$ https://umayaika.wordpress.com/2012/04/24/albert-einsteinagama-tanpa-ilmu-adalah-buta-ilmu-tanpa-agama-adalah-lumpuh/, diakses pada tanggal 3 Februari 2017.

Musdah Mulia, Islam dan Hak Asasi Manusia: Konsep dan Implementasi, (Yogyakarta, Naufan Pustaka, 2010)

Nanang Wijaya, Agama Filsafat Klasik, https://jalanpencerahan.wordpress.com/artikel/agama-dalam-filsafat-klasik/, diakses pada tanggal 3 Februari 2017.

Radhar Panca Dahana, Jejak Posmodernisme: Pergulatan Kaum Intelektual Indonesia, 
(Yogyakarta, Bentang, 2004)

Rahmanhadiq, Al Qur'an dan Sains tentang Rotasi Bumi, http://www.qiroatipusat.or.id/2015/06/al-quran-dan-sains-tentang-rotasibumi.html, diakses pada tanggal 3 Februari 2017.

Syaikh DR. Shalih bin Fauzan Al-Fauzan, Kitab Tauhid 1, (Jakarta, Darul Haq, 1998) 